\title{
On Exploring Flipped Classroom Teaching Mode Based on the Development of Information Technology
}

\author{
Huanhuan $\operatorname{Ren}^{1, a^{*}}$, Chi Ma ${ }^{2, b}$ \\ ${ }^{1}$ Teaching and Research Institute of Foreign Languages, Bohai University, Jinzhou 121013, China \\ 2 Jinzhou Institute of Forestry Research, Jinzhou Forestry Bureau, Jinzhou 121013, China \\ arenhuanhuan2014@163.com, ${ }^{\mathrm{b}}$ machi2014@tom.com
}

Keywords: Flipped classroom; Teaching mode; Information technology

\begin{abstract}
Many schools at home and abroad have employed the flipped classroom model to great success and recently going for a flipped classroom is becoming a true fad in educational scenarios. This is made evident by the fact that constructive theory, humanistic education and learner autonomy constitute basic rationales for the adoption of flipped classroom teaching mode. Through the use of information technology, four main things in pedagogy may be transformed or inverted through flipping classroom, including the subversion of learning time and place, the subversion of instructional model, the subversion of responsibility and power, and the subversion of personal relationship. It's hoped that flipped classroom teaching mode may have the potential to redefine how instructors deliver learning and education and become potentially one of the most successful teaching strategies for the future.
\end{abstract}

\section{Introduction}

There is a global trend towards going to flipped classroom teaching mode, and the advances in information technology unlocks new possibilities for flipping classroom in most fields. Recently moving towards a flipped classroom is catching on among people in educational scenarios. Thus what makes the flipped classroom such a groundbreaking idea? Is there any proof that flipping the classroom actually works? This paper will analyze briefly from the ideas behind flipped classroom, basic rationales for the adoption of the flipped classroom and the exploration of flipped classroom through the use of enabling information technologies, so that benefits of flipping classroom may accrue to some extent in specific pedagogical practice. This article is a summary of this research work, hopefully provids theoretical support and guidance for instructors who are going for a flipped classroom in future practice.

\section{The Ideas behind Flipped Classroom Based on the Development of Information Technology}

Definition of Flipped Classroom. The concept of "flipped classroom", which is also known as "inverted classroom", "flipped instruction", "reverse teaching" or "backwards classroom", originally comes from America by Woodland Park High School teachers Jonathan Bergman and Aaron Sams in 2000. Usually, once a new idea becomes a buzzword, pinning down the definition can be usually an necessary work. Flipped classroom is, simply stated, an environment where what was formerly classwork or lectures has become online video presentations that students view outside of class, and what was formerly homework is now classroom interaction with the teacher and students [1]. As you can see, the idea behind the new pedagogical method is just flipping the whole thing around. This teaching model is, in essence, a mixture of direct instruction and constructivism [2]. It represents a unique combination of learning theories once thought to be incompatible-active, problem-based learning activities founded upon a constructivist ideology and instructional lectures derived from direct instruction methods founded upon behaviorist principles [3]. Although shortcomings still exist in this new teaching model, it will be improved in the development in the future [2]. In sum, flipping the classroom means completely re-thinking how to do the job people have done a certain way for 
years, and educators from around the world are experimenting with the idea of a flipped classroom model for promising results.

Replacement for Traditional Classroom. Flipped classroom is turning the traditional classroom on its head. Due to poor learning outcomes brought about by traditional classroom, the practice of flipped classroom, a new model of teaching, emerges in many colleges and schools. Something wrong with traditional classroom. It's concurred that the traditional one-size-fits-all model of education often results in limited concept engagement and severe consequences [4]. Lage, Platt, and Treglia initiated their experiment in response to the observation that the traditional lecture format is incompatible with some learning styles [5]. It could be found that, in traditional classroom, students have limited information about what to expect until the very end of the class and what they do is to follow along [4]. Without discussions and hands-on activities, learners tend to lose their interest in learning and their learning outcome is damaged. In flipped classroom, however, students don't have to stay focused during a long lecture and they have specific questions in mind to guide their learning and practice performing the skills they are expected to learn [4]. Ideas can be presented in a number of ways and students appear more motivated than when the course is taught in a traditional format. In brief, flipped classroom transformed learning for their students since it opens up additional time in class for more productive, interactive activities than the lectures teachers have been giving.

The Rise of Information Technology. One key factor driving increased adoption of the flipped classroom model is information technology applied in it. Flipped classroom entails the involvement of information technology. One of the common criticisms leveled at flipped classroom teaching mode in the past was the weak support of educational technologies behind flipped classroom. The most frequently asked question is "What about all the students who don't have a computer at home to watch videos on?"or "What to do when students don't have technology at home?" However, with the advance and pervasion of information technology in recent years, it's no longer the problem of flipped classroom. It's found that few people just don't have the access required for the model to really work, and it's easy for students to reach for everything loaded to the Internet on mobile devices as well as desktops. We can say that, information technology as one specific innovator influences student learning environments in fundamental ways, and plays a key role in influencing the creation and adoption of the flipped classroom model. But it's concurred that flipping classroom is, after all, not a matter of technology, but a matter of education itself. In brief, the availability of online video and increasing student access to technology has paved the way for flipped classroom models. The truth is that, with technology constantly developing, there is no reason why flipped learning should not also evolve alongside it.

\section{Basic Rationales for Flipped Classroom Based on the Development of Information Technology}

Constructive Theory. The flipped classroom model is congruent with the current constructivist approach to learning. Constructivism advocates discovery learning where students use information they already know to acquire more knowledge [6]. In other words, humans make meaning in relation to the interaction between their experiences and their ideas. Through the process of flipped classroom, learning content is given context as it relates to real-world scenarios, and discussions are led by the students where outside content is brought in and expanded. By flipping classroom, students learn by incorporating understanding of the subject into their existing knowledge base [7]. Moreover, social constructivist scholars view that individuals make meanings through the interactions with each other and with the environment they live in. Flipped classroom is not the idea that students working in isolation and it are a class that increases the interaction between students an teachers. Flipped learning allows for a much more interactive classroom lesson, with the teacher helping students when they are stuck as opposed to students passively listening to lectures and taking their assignments home afterwards. Under the clipped classroom model, rich contact between students and teacher increases as learners keeps more in touch with instructors and peer students for exploratory questions and timely feedback outside school day. 
Humanistic Education. The flipped classroom model allows for humanistic education. Flipped classroom is a place where all students can get a personalized education. Learning outside school day allows for differentiation-plan for the extremes and the middle. Teachers review questions with students individually through classroom activities, and students can have teachers guiding and coaching them and get the immediate classroom support they need. It is proposed that the teacher's role is less that of transmitting knowledge, more that of facilitating learning in less directive ways. What's more, flipped classroom is person-oriented education. For students who really struggle with an assignment they can go back and relearn the information at anytime, or if the student needs to be reminded of something this will give the easy access to the content. And for students who miss a day, they can easily check what their groups members did while they were gone. It's a classroom where absent and weaker students do not get left behind. With teachers encouraged to give students choices, students has the option of reviewing the lessons at home and bringing any questions they have to the classroom. This means learners get less frustrated in language learning and therefore less likely to drop out of their studies under the flipped classroom model.

Learner Autonomy. Flipped classroom, in essence, is learning that is centered around the student. In the process of flipped classroom, students assume greater responsibility for developing their own learning track. With students in her classroom better at taking the lead on pursuing learning process and outcomes, learners shift their focus to passively listening to lectures to actively how to learn better on their own. It's believed that students may be highly engaged in their learning through making informed decisions and proactive actions by themselves. That is, it's an environment where students take charge of their own learning and are given more opportunities to learner by themselves. Besides, through going to flipped classroom, students are allowed to show their mastery of learning content and learning way they prefer. Students may take ownership of the material and use their knowledge to lead one another without prompting from the teacher. It has the benefit of allowing students to work through subject matter at their own pace as students don't all learn at the same pace and in the same ways. By finding valuable resources and pursuing learning their own way, students are actively engaged in problem solving and critical thinking that reaches beyond the traditional scope of the course. All in all, learners are expected to tap into the content and lessons beyond those instructors have developed and they have the freedom to delve beyond core curriculum under the clipped classroom model.

\section{The Exploration of Flipped Classroom Based on the Development of Information Technology}

The Subversion of Learning Time and Place through Flipped Classroom. Learners can not only study in school day, but also learn outside of school day. Going to flipped classroom is a thing that may totally invert learning time and learning place. In flipped classroom, instruction and lecture are not the daily activities in classroom, but rather are delivered online especially through videos outside of classroom. In other words, learners can listen to teachers' lecture at the time which is convenient for them, and class time is spent doing construction and practice of the knowledge learned which is usually regarded as homework in traditional classroom teaching method. This allows students to get individual time in class to work with their teacher on key learning activities. That is, a flipped classroom frees up time in the physical classroom to apply the material just learned. What's more, learning, under the clipped classroom model, is not confined to a fixed learning place, for example physical classroom, language laboratory, etc. Due to enabling mobile technologies, learning can take place at any place with smart multimedia (e.g. mobile phone, iPad, etc.), as long as instructor posts additional explanations and resources as necessary and grades higher quality work. Learners can do their learning wherever works best for them whilst class time devoted to collaborative projects, answering questions, and engaging with the material on a deeper level. In brief, learning time and place is inverted under the flipped classroom model with students watching lectures at home, online, and class time being reserved for collaborative activities that increase engagement. 
The Subversion of Instructional Model through Flipped Classroom. Flipped classroom is forcing teachers to reflect on their practice and rethink how they teach their students. The instructor is supposed to be reminded that flipping is only the beginning, and there's no one right way to flip a classroom or lesson. Most notably, teachers have to change the way they've always done things in classroom. For centuries, this has been the way that school's been done. Now it's a time for a change. Generally speaking, the teacher is to move the more passive elements of learning outside of the classroom, so that more class time is available for interactive, hands-on learning. It's argued that teacher is not like sage on the stage, standing and delivering lecture and assign homework, but teacher's role is to guide on the side [7]. Meanwhile, it's inspiring instructors to bring technology into their physical classrooms and virtual classrooms through the use of audiovisual aids. As long as teachers reflect mostly on what they are doing and try to make a true and positive change in methodology and pedagogy under the flipped classroom model, the subversion is already half done. The gist of flipping the classroom is that instructors completely re-think how to do the job they have done a certain way for years. In sum, flipped classroom is about changing instructional models, promoting teachers to reinforce and delve more deeply into new teaching methods and strategies so that learners can obtain pleasant and productive learning outcomes with the aid of information technology.

The Subversion of Personal Relationship through Flipped Classroom. Flipped classroom adds a much larger social element since learners can interact with other students and educators beyond classroom. The subversion of personal relationship through flipped classroom can be denoted in two dimensions. On one hand, the relationship between the teacher and the learner is enriched through the use of information technology. In the old times, one-way teacher-student communication dominates the classroom, and it's harder for them to find more opportunities to reach for each other. By going to a flipped classroom, learners start connecting and collaborating with the educators worldwide who are passionate about flipped learning. Instructors can easily give students assignments through the Internet or the wiki, etc, for both individual and group projects, and gather the information they need to facilitate learning process. This approach supports instructors playing their most important role of guiding their students to deeper thinking and higher levels of application. On the other hand, various learning communities are established among learners themselves. As a result of students taking responsibility, interacting meaningfully with their peers can become a norm in learning, and students can easily collaborate on their projects outside of the school day. In this process, multimedia is proposed to be especially utilized by learners who are savvy at information technology. In sum, rich teacher-student communication and learning community are built and enhanced through the process of flipping a classroom based on the development of information technology.

The Subversion of Responsibility and Power through Flipped Classroom. Teachers nowadays are much more aware of the importance of the shift of learning responsibility in flipped classroom teaching mode. On the surface, it's about shifting from passive learning to active learning, or say, the learner from passive recipient to active constructor of knowledge. The gist is, however, about the matter of responsibility in learning. It's expected that learners should take more responsibilities as opposed to being simply controlled and managed by teachers in learning process. Only learners are willing to take charge of their learning and take informed learning actions, can they be active and autonomous learners in foreign language learning. What's more, what flipped classroom describes is, in essence, learning that is centered on the student, not the teacher. It's a matter of learning rights and learning authority. Under flipped classroom learning model, learners can possess more freedom in the learning process. For instance, learners can choose whatever way works for them and can learn at any pace, at any time and at any place they like in virtual classroom. Their choices in physical classroom are enriched and they can have more opportunity and possibility to grow and develop in foreign language learning. In a word, flipped classroom entails learners to have more responsibility and power over the way and process by which they study and learn so that they can make informed decision and proactive action in the foreign language learning process. 


\section{Conclusion}

From above, one can see that going for a flipped classroom is becoming a true fad in educational scenarios. This is made evident by the fact that constructive theory, humanistic education and learner autonomy constitute basic rationales for the adoption of flipped classroom teaching mode. Based on the development of information technology, four main things in pedagogy may be transformed or inverted through flipping classroom, including the subversion of learning time and place, the subversion of instructional model, the subversion of responsibility and power, and the subversion of personal relationship. It's hoped that flipped classroom teaching mode may have the potential to redefine how instructors deliver learning and education and become one of the most successful teaching strategies for the future.

\section{Acknowledgements}

This work is part of the project of On Cultivating and Developing Liaoning Scientific Foreign Language Talents with View to Bourdieu' Theory, the project of On Establishing Generative Mechanism of EFL Autonomous Learning Behaviors and Strengthening Development of Learning Field in Ubiquitous Learning Space, and the project of On Constructing Mechanism and Strategies for College English Autonomous Learning Abilities via Mobile Multimedia. This research was supported by the fund of Liaoning Planning of Philosophy and Social Science (Project No. L16CYY001), the fund of Liaoning Provincial Federation Social Science Circles (Project No. 2017lslktyb-019), and the fund of the Thirteenth Five-Year Plan of Education Sciences of Liaoning Province (Project No. JG16DB013).

\section{References}

[1] A. H. Marcus, Flipping the Classroom: Teachers Turn "Homework" on its Head, Educational Technology, May 24, 2012.

[2] J. Bergmann, A. Sams, Flip Your Classroom: Reach Every Student in Every Class Every Day, Washington DC: International Society for Technology in Education, 2012.

[3] J. Bishop, M.A. Verleger, The Flipped Classroom: A Survey of the Research, 120th ASEE Annual Conference \& Exposition, 2013.

[4] F. Strayer. The Flipped Classroom: Turning the Traditional Classroom on its Head, Flipped Class Conference, 2011.

[5] M. J. Lage, G. J. Platt, M. Treglia, Inverting the classroom: A gateway to creating an inclusive learning environment, The Journal of Economic Education, (4) 2000.

[6] K. Alesandrini, L. Larson, Teachers bridge to constructivism, The Clearing House, 2002.

[7] A. King, From Sage on the Stage to Guide on the Side, College Teaching, (41) 1993. 